\title{
La mujer y el mal
}

\author{
GRACIELA HIERRO \\ UNAM, México
}

\begin{abstract}
Hay un principio bueno que cres el orden, la luz y al hombre, y un principio malo que creo el caos, la obscuridad y a la mujer.
\end{abstract}

PThacoras

El interés central de este trabajo es la reflexión sobre el mal moral desde el punto de vista de las mujeres, conocedoras intuitivas del problema por haber estado involucradas en la maldad desde los remotos tiempos de la caja de Pandora, Eva, las manzanas y las serpientes; unidas o por lo menos más susceptibles al mal por nuestra «debilidad natural» frente a los asuntos carnales.

Iniciaré el trabajo con un análisis somero de la concepción tradicional del mal. En seguida me referire a la interpretación mítica y religiosa del origen del mal moral; luego plantearé la respuesta de las mujeres desde el análisis de los mitos, la teología feminista, la filosofía y la ciencia social, desconstruyendo la unión de mujer y mal. Cerraré el artículo sobre la posibilidad de superación de este estado de cosas, con una reflexión ética feminista que apunta a una utopía.

¿Para qué hablar del mal y no del bien? Para atacar la mistificación del mal en todos sus avatares - los antiguos por conocidos, y los nuevos por inesperados-, el mal en nosotras, en los otros, en las divinidades que veneramos. Para sufrirlo menos y vivir una existencia más serena frente al terror de su amenaza. Para advertir el peligro de los medios que se nos proponen en este fin de milenio para huir del dolor: el satisfactor inmediato, la fuga por el consumismo, y sobre todo la veneración del poder jerárquico, tecnológico, del robot omnipotente y aniquilador, que ha sustituido al viejo "terror ético" de los diablos sueltos por el mundo.

Tradicionalmente la explicación del mal aparece bajo diversos saberes: en la mitología que relata alegóricamente los grandes hechos naturales e históricos del origen y el fin del mal; en la teodicea en la que habla de la justicia divina que enfrenta la necesidad de conciliar sla realidad obvia del mal con el postulado de la existencia de un Dios omnipotente, omnisciente y de bondad absoluta" e intenta rescatar a Dios de su posible complicidad con el mal (Noddings, 1989, p. 9). En la teología que enfoca el problema desde las «ciencias» de la religión; y también las ciencias humanas que explican el origen del mal se refieren al origen del mal, desde el alma, la sociedad o la esencia tal como hace la filosofía.

\section{La taxonomía del mal}

Se acostumbra distinguir entre el mal natural, el mal cultural, el moral y el metafísico. Natural se considera la enfermedad, la vejez y la muerte, unidos a cataclismos de cualquier orden que precipitan el mal físico que finalmente se traduce en dolor. El mal cultural lo constituyen la pobreza, el racismo, la guerra, el sexismo y la discriminación por la edad, entre otros. El mal moral se levanta por la desobediencia al dios al que nos consideremos sujetos, y cuya ira propicia el terror ético, fundamentado a su vez en el mal metafísico." 
Sabemos que generalmente el mal se define por oposición al bien y es globalmente lo que siempre hay que rechazar. El mal moral se mide frente a un bien definido por los valores y las normas morales del clima de opinión que prive.

\section{El mal moral}

Uno de los grandes relatos del Occidente es sin duda el del mal moral. Forma parte de la monumental explicación racional de la realidad, que se conoce como el humanismo cristiano que conforma la mentalidad patriarcal. El problema del mal humano, en esa perspectiva, se escribe casi exclusivamente por los hombres y se define en términos de mancha, pecado y culpa (Ricoeur, 1988).

Se considera que el mal moral es el resultado de la debilidad fundamental de la naturaleza humana, de la incapacidad que tenemos para dominar la pasión. Y, por tanto, el "sexo débil» por antonomasia, es el que falla más. Las mujeres estamos siempre a merced de nuestra pasión. ¿Cómo negar que somos a-pasionadas?

Los hombres necesitan aliviarse de la culpa colectiva y su responsabilidad del sexismo, precisamente porque viven en una relación íntima con nosotras. De alli que los mismos hombres hayan creado las explicaciones míticas, religiosas, filosóficas y científicas, que pretenden justificar la opresión femenina, producto, en el caso analizado, de la unión mujer y mal. En otras palabras, somos para los hombres las merecedoras de la opresión por nuestra perversidad anímica y física, las portadoras de la culpa, las incitadoras del deseo masculino, las castradoras del Edipo, en suma, las brujas y las feministas.

\section{La respuesta de las mujeres}

"Yo la peor de todas..." (Sor Juana Inés de la Cruz. Filosofía feminista).

En el mito y en la imaginación popular, las mujeres han estado unidas al mal como forma csencial de ser. En la mitología, en diversas tradiciones que se refieren al inicio del mal en el mundo humano, la mujer tiene una misión protagónica y se simboliza como la culpable de la maldad inicial. El mito de los inicios se comprende como una narración tradicional, que se relaciona con eventos que sucedieron al principio de los tiempos y que tiene el propósito de establecer todas las formas de acción y pensamiento por las cuales las personas se comprenden a sí mismas en su mundo. Los mitos hablan del principio y también del fin del mal. El mito del principio relata la relación de la persona con lo sagrado, que se rompe por la entrada del mal y se restablece con su fin (Ricoeur, op. "cit.* p. 5). Si las mujeres inician el mal será la acción de los hombres la que devuelve el bien.

\section{Conclusión primera}

"Se necesita estar loco para ser mujer» (Un poeta).

En esa secuencia los saberes patriarcales situaron y fijaron ontológicamente el principio femenino obscuro y peligroso encarnado en las mujeres concretas como alo otro". Por ello somos seres carentes de aseidad (ser), precisamente por constituir alo otros; de identidad, por carecer de lenguaje, sin finalidad propia por ser las subalternas. El otro lado de la medalla de lo que sí es: del ser idéntico, pleno de sentido, luminoso, encargado de la salvación humana (dos veces: Job y Cristo) dando fin al mal, y en lo cotidiano el dictador de los arreglos sociales, 
creador de la cultura, en una palabra los hombres, que no somos nosotras.

Lo anterior se funda, en última instancia, en la creencia que nos es tan familiar de que el bien es el ser. De acuerdo con la teología cristiana leída por san Agustín, nuestro "no ser" finalmente nos unió entrañablemente con el inicio del mal.

El cuerpo femenino valida con razones concretas, comprobables, empíricas y físicas la unión mujer-mal; se basa en los avatares de nuestra biología: los misterios de la menstruación y la procreación. Nuestro estado morboso que obedece a nuestra condición de eternamente "enfermas" histéricas, victimas de la matriz que produce - además de niños- locura. "Enfermedades" mensuales que desembocan en el "alivion del parto y terminan en el limbo inefable de la menopausia. También se debe a nuestra anatomía con el sexo escondido, húmedo $y$ al parecer profundamente peligroso - recuérdese la svagina dentada" y otras adivinaciones semejantes-.

El binomio, o más bien el síndrome mujer-mal ocurre asimismo por razones históricas: la rebeldía de Eva y Pandora que heredaron grupos de mujeres como las beguinas, las brujas del Medievo, todas las que eligieron unirse al demonio para luchar contra el orden patriarcal. Conocemos cómo terminó esa historia, en las hogueras, aplastadas por El martillo de las brujas (Malleus maleficarum).

Las intelectuales feministas son contestatarias de la interpretación anterior, en lo que puede considerarse la cuarta ola del feminismo correspondiente al fin del milenio. ${ }^{2}$ Coincidente con el posmodernismo se escribe la cultura feminista que interpreta "el lenguaje de la Diosa" (cf. Marija Gimbutas, The Language of the Godess $\mathrm{y}$ Riane Eisler, The Chalice \& The Blade) y surge la nueva visión del mal moral desde la experiencia femenina, con el propósito de enfrentar la misoginia que encubre la teología patriarcal y de elaborar la cultura de la diferencia que articule nuestra práctica social femenina.

\section{La teología feminista y el mal}

Los estudios religioso-históricos emprendidos por las mujeres muestran la veneración a las diosas. Hay evidencia de que a partir del neolítico, en los comienzos de la civilización antigua, se encuentra por doquiera la imagen difusa de la Diosa, sin acompañamiento del culto de un dios masculino. E. $O$. James, en su libro clásico El culto de la diosa madre, afirma que esta veneración es una de las más antiguas y de mayor sobrevivencia en las religiones del mundo antiguo (citado en R. Radford, 1983, p. 470).

Tanto en la tradición hebrea del "Génesis» como en la creación platónica del Timeo, se habla de una materia primitiva ya existente, a la que le da forma el dios creador. $Y$ esta materia se torna el punto más bajo en la jerarquía del ser. Así, la jerarquización de dios-hombre-mujer, no sólo hace a la mujer secundaria en relación con dios; también le confiere una identidad negativa en relación con lo divino. Mientras el hombre es visto esencialmente como la imagen del dios masculino trascendente, la mujer se contempla como la imagen de lo más bajo, como la representación de la naturaleza material. Aunque ambos, hombre y mujer, son vistos por la teología cristiana como "naturalezas mezcladas", la identidad masculina apunta hacia lo celeste y la femenina a lo subterráneo, a lo telúrico de la "madre naturaleza".

El género se convierte en el símbolo primario del dualismo de trascenden- 
cia e inmanencia, espíritu y materia, hombre-mujer. Con la derrota de la diosa por el dios hombre se consuma la unión de la mujer con la tierra. Es la madre naturaleza, la madre tierra, la "Pacha mama" de los Incas. Lo terrestre frente a lo celeste y luminoso que es el principio masculino racional creador y regidor de lo existente: lo apolineo.

Es en la teología cristiana donde aparece más clara la unión del mal con la mujer, propia de la religión monoteísta patriarcal que representa, en el cielo, la derrota de las viejas religiones de las diosas madres. Nuestra Coatlicue es un claro ejemplo de esta afirmación. Ella es la figura prístina del panteón azteca "madre de los diosesn, origen de todo lo existente, derrotada primero por Huitzilopochtli su hijo y luego, al identificarse con María de Guadalupe, por Cristo. «María bendita entre todas las mujeres...»

En el imaginario patriarcal somos las más malas, pero también podemos ser las más buenas. Carentes de ser, pero dadoras de ser. Nuestra salvación es la maternidad dentro de los límites establecidos por el patriarcado. Somos portadoras de los rasgos esencialmente femeninos de cuidado y nutrición; ambos rasgos: maldad y bondad «intrínsecas» han servido como medios de control. Bondadosas por obedientes y viviendo vidas de servicio. Aunque es difícil referirse a las mujeres en conjunto en vista de nuestras diferencias, tenemos en común la experiencia doméstica de responsabilidad, en el cuidado, mantenimiento y nutrición de nuestras familias.

La bondad femenina es utilizada como forma de control de las mujeres. Somos las "buenas" por la maternalidad; por el cuidado y atención a los otros se nos ha considerado el «ángel del hogarn. En suma, o somos malva- das por la atracción que tenemos hacia los asuntos "carnales", o la encarnación de la bondad misma por nuestros rasgos naturales de procreación que conllevan la compasión y el cuidado. Esta circunstancia ha propiciado la subordinación de las mujeres, por malas o por buenas. Ambos rasgos, bondad o maldad, han servido como medio de control que nos ha hecho sentir bondadosas por obedientes, por vivir nuestras funciones de servicio a los otros; en el orden patriarcal sólo la obediencia nos dignifica. Además de la obediencia, hemos de ajustarnos al modelo de vida que nos ofrece el patriarcado.

\section{La filosofía feminista}

Simone de Beauvoir, en El segundo sexo, plantea el problema del mal desde el punto de vista filosófico. $Y$ asi dice que, al institucionalizarse el orden patriarcal del reino del padre, el patrón y el padre eterno, el hombre se afirma como sujeto libre, dando origen al "otron: la mujer. Desde ese momento la relación con el otro es dramática. La existencia del otro se convierte en un reto, peligro y desafío. El surgimiento de la filosofía griega muestra que la alteridad, la otredad es la negación y por tanto el mal. Al postular al otro se define un maniqueismo: el bien se opone al mal por principio. El otro es la pasividad confrontando a la actividad. La diversidad que destruye la unidad. La materia que se opone a la forma. El desorden frente al orden. Así, la mujer se identifica con el mal y por ello es sujeto de la hostilidad masculina. La hostilidad refleja también el miedo. La desconfianza frente a su ambivalencia en el poder. Si primero se le consideró sagrada, luego fue impura. Eva fue el regalo de Jehová para Adán, y luego se convirtió en la causa 
de la ruina de la humanidad. Los dioses paganos cuando desean vengarse de los hombres crean a la mujer. $Y$ la primera mujer fruto de esta creación es Pandora, la que desata el sufrimiento de la humanidad. La historia de Pandora, relatada por Hesiodo en Los trabajos y los días, la pinta como el instrumento contra los hombres, para castigar a Prometeo que roba el fuego a los dioses. Hesíodo describe a Pandora como la poseedora de todas las gracias femeninas, pero llena de ufalsedad, pensamientos traidores y naturaleza ladronar.

Por la ley de los contrarios, el bien requiere del mal, y el hombre de la mujer. Para satisfacer sus deseos, para perpetuar su estirpe, la mujer es indispensable. Por ello hay que conferirle su lugar en el orden social, en tanto que acepte el orden cstablecido por los hombres y no intente cambiarlo. Sólo así podrá recobrar su valor perdido. Con otras imágenes después de la "caída", 'no será ya la diosa creadora, tampoco la indomable amazona, ni la reina poderosa. Será la virgen, la casta y obediente esposa, la madre de Dios y los hombres. Esta ambivalencia la acompaña hasta nuestros días. En gran medida seguimos siendo "lo otroy, la sierva del hombre (Beauvoir; 1939, pp. 231 y ss.)

\section{La psicologia feminista}

Tradicionalmente a las mujeres se las ha considerado, si no unidas al mal, por lo menos susceptibles a éste, más que sus compañeros. Noddings (1989, p. 39) explica que el origen de sentir a la mujer como la encarnación del mal radica básicamente en el deseo que el cuerpo femenino levanta en los hombres, al considerar ellos su propio deseo como malo y no poder soportarlo, lo localizan en lo deseado: ella. El mal se filtra por su cuerpo y se refleja en el inconsciente femenino que es ala entrada del demonion, y así se demonologiza el sexo.

\section{Del mito a la antropología feminista}

Los mitos de la maldad femenina se encuentran enraizados en los estratos más antiguos de la cultura humana. Un lugar temprano pueden haber sido los ritos masculinos de la pubertad, en los cuales, al ser iniciado violentamente en el mundo masculino, el hombre se separa del mundo femenino y sufre la separación de la madre. Allí se originan los cuentos de la maldad del matriarcado, y de su contrapartida, la bondad del sometimiento a lo masculino para mitigar el dolor de la ruptura (Noddings, 1989, p. 39).

Sin duda el mito de Eva tuvo mayor impacto cultural que el de Pandora. Está «sostenido" por la teología cristiana y hebrea, que adquiere su visión perfecta en la teología de Saúl de Tarso, san Pablo confirma la maldad femenina. Pablo eleva la idea del pecado a sus límites más extremados. La interpretación de san Agustín y sus sucesores marca la "caída de Adán* como la alienación del bien. La necesidad de la redención por la encarnación y la muerte de Cristo-Dios. Así, el chivo expiatorio Eva, no sólo es la causante de la caída de Adán, lo cual hace que las mujeres, sus hijas, sean las culpables de la impotencia radical del «hombre" frente al mal. Suceso sólo rescatable por la muerte de Cristo. Llevando la culpa de las mujeres a sus últimas consecuencias: a causa de las mujeres Cristo debe morir en la cruz.

\section{La historiografia feminista}

El relato, a vuelo de pájaro, de lo sucedido en el mito: Pandora, Eva, Lilith la 
esposa rebelde de Adán. En los movimientos de mujeres: las beguinas, las brujas, las sufragistas, $y$ ahora las feministas, podemos reconocer la población de las rebeldes, las transgresoras del orden patriarcal, con las consecuentes venganzas masculinas.

\section{La ética feminista}

La teoría feminista de la diferencia advierte que hombres y mujeres no somos iguales en lo que creemos, en lo que deseamos, en lo que hacemos, y en cómo lo hacemos. Pero diferencia no se lee como jerarquia. También advierte que las mujeres no somos wlas idénticas» unas y las otras (cf. Amorós, 1988); somos diferentes, tenemos identidad propia, valer propio, intereses y saberes propios, que se validan por el mismo colectivo de mujeres, fundamento de una ética feminista del placer.

En esta ética se plantea el deber de superar el desajuste primario de la relación interpersonal hombre-mujer; también la consideración de que la desigualdad masculina y femenina signifique jerarquía, es decir, superioridad - frente a la inferioridadque ofrece la norma de lo humano en el arquetipo masculino, como hemos visto, relatada en los mitos de la inferioridad femenina y de su pretendida maldad asociada a la materialidad de la naturaleza; todo lo cual corresponde a la supuesta esencia del ser femenino. La imaginación cotidiana nos configura como origen y perpetuación de estas ideas y prácticas acerca del mal, tal como se nos hace creer en ellas en la socialización genérica.

La desobediencia al patriarcado es el mal de la transgresión a la ley divina, a la ley del estado, a la del padre o el jefe. Si construimos la fenomenología del mal desde el feminismo, esta teori- zación nos permite analizar su mitología. Vemos que en cierta forma es diferente a la mitología masculina. El análisis del mal advierte de inmediato en todos nosotros el miedo al dolor, $y$, específicamente en las mujeres, el miedo a la separación y al desamparo producto de la impotencia; estas son las categorias del mal más temidas por las mujeres. Nosotras somos las encargadas seculares de cuidar la vida de relación en la familia por nuestra calidad de procreadoras-nutricias. Con estas tres categorias: dolor, impotencia y separación, se pueden examinar las formas naturales y culturales de la moralidad del mal. La finalidad práctica, como ya advertí, es la posibilidad de alcanzar el desarrollo educativo apropiado para enfrentar la inevitabilidad del mal, en nosotras mismas y en nuestra vida de relación, creciendo espiritualmente hacia el placer (cf. Graciela Hierro, De la domesticación a la educación de las mexicanas).

\section{La utopía feminista}

"Todos somos iguales, aunque unos más que otras" (Orwell, Animal Farm).

La utopía arranca del deseo de superar la desigualdad genérica, estableciendo relaciones simétricas con el otro género. Para ello existe la necesidad de potencializar al colectivo femenino. Una forma que puede ayudar a lograrlo, a mi juicio, consiste en desenmascarar la misoginia en todos sus avatares. En este trabajo se intentó la desidentificación del binomio mujer y mal. Cuando alcancemos la igualdad de los géneros, tal vez podremos inventar nuevas formas de unión entre los géneros, que nos permitan gozar de la relación de hombre y mujer.

El propósito primario de este ensayo ha sido develar el mal en la forma que se esconde y desprende de la misoginia 
y no de desconocer el mal en todos sus avatares. Las mujeres y los hombres hemos de convivir con la inevitabilidad del mal o su gratuidad, como apunta Hanna Arendt. En cada época hemos de buscar formas de relación entre los géneros que nos ayuden a subsistir de manera más serena y pacífica, con nosotras mismas y los demás. Y esa es la Utopía que perseguimos las feministas. El amor mutuo como fundamento de la ética del placer.

\section{BIBLIOGRAFIA}

Amoros, C.: Mujeres, feminismo y poder's, en Forum de Política Feminista, Madrid, 1988.

Beauvolr, S.: Le Deaxieme Sexe, Paris, Gallimard, 1949.

HIERRo, G.: De la domesticación a la educacion de las mexicanas, Ed. Fuego Nuevo, 1989.

Radford RuEther, R.: Sexism and God-Talk, Boston, Beacon Press, 1983.
Noddings, N.: Women and Evil, Ltd. Bcrkeley y Los Angeles, Calif., University of California Press, 1989

Rucoeur, P.: The Symbolism of Evil, Boston Beacon, Press, 1969.

Phulrs, J. A. Eva. La historia de una idea, México, Fondo de Cultura Económica, 1984.

\section{NOTAS}

1. El mal metafísico se apunta, cuando la divinidad constituye la suna bondad, entonces urge la necesidad teológica de descubrix el fundamento del mal. Entramos de lleno en la teodicea y encaramos la posible no reducción del mal. Porque el mal cxiste y no puede disolverse en conceptos que supongan su redencion. Hemos de enfrentar tambiên el terror ético que surge y se encierra en la falta trascendente que es el pecado. Después de la Carda se levanta el miedo a la transgresión y su castigo que puede ser eterno. El paso del terror al dolor y la muerte es el terror ético que se vive como el salto de lo maléfico "natural a la transgresión contra la ley del Dios, el pecado, la culpa, la impureza y la falta, que se castiga con el sufrimiento en la vida, y la posibili- dad del infiemo eterno. Pensemos en un "Auschwitz» para siempre.

2. La primera ola del feminismo se remonta a Lysistrata, hasta la defensa socrática y platónica de las mujeres gobernantes. Pasando por las Beguinas y las brujas del Medievo. La segunda arranca de la Revolución Francesa y la lucha abolicionista en los Estados Unidos de Norteannérica, que culmina con el sufragismo de los siglos xux.xx. La tercera en 1970 con el resurgimiento del movimiento de mujeres a la buisqueda de una nueva identidad femenina a partir de la filosofia de Simone de Beauvoir. En esta cronologia, la cuarta etapa del feminismo corresponde al fin del milenio, con caracteres propios en los que no vamos a entrar aquí. 